University of Nebraska - Lincoln

DigitalCommons@University of Nebraska - Lincoln

Faculty Publications from the Harold W. Manter Laboratory of Parasitology

$2-1973$

\title{
Structure of the Oocysts and Excystation Processes of Four Eimeria spp. (Protozoa: Eimeriidae) from the Colorado Pika, Ochotona princeps
}

Donald W. Duszynski

University of New Mexico, eimeria@unm.edu

John T. Brunson

State University of New York College at Oswego

Follow this and additional works at: https://digitalcommons.unl.edu/parasitologyfacpubs

Part of the Parasitology Commons

Duszynski, Donald W. and Brunson, John T., "Structure of the Oocysts and Excystation Processes of Four Eimeria spp. (Protozoa: Eimeriidae) from the Colorado Pika, Ochotona princeps" (1973). Faculty Publications from the Harold W. Manter Laboratory of Parasitology. 118.

https://digitalcommons.unl.edu/parasitologyfacpubs/118

This Article is brought to you for free and open access by the Parasitology, Harold W. Manter Laboratory of at DigitalCommons@University of Nebraska - Lincoln. It has been accepted for inclusion in Faculty Publications from the Harold W. Manter Laboratory of Parasitology by an authorized administrator of DigitalCommons@University of Nebraska - Lincoln. 
THE JOURNAL OF PARASITOLOGY

Vol. 59, No. 1, February 1973, p. 28-34

\title{
STRUCTURE OF THE OOCYSTS AND EXCYSTATION PROCESSES OF FOUR EIMERIA SPP. (PROTOZOA: EIMERIIDAE) FROM THE COLORADO PIKA, OCHOTONA PRINCEPS
}

\author{
Donald W. Duszynski and John T. Brunson \\ Department of Biology, University of New Mexico, Albuquerque, New Mexico 87106 and \\ Department of Zoology, State University College, Oswego, New York 13126
}

\begin{abstract}
Oocysts of Eimeria banffensis Lepp, Todd, and Samuel, 1972, Eimeria cryptobarretti sp. n., Eimeria princepsis sp. n., and Eimeria calentinei sp. n. are described from the Colorado pika, Ochotona princeps, collected from 3 mountain sites in Colorado. Subspherical oocysts of E. banffensis measure 23 to 34 by 18 to $25 \mu$ (mean 27.6 by $23.0 \mu$ ) with ovoid sporocysts 10 to 16 by 7 to $10 \mu$ (mean 12.5 by $8.5 \mu$ ). A micropyle, oocyst residuum, and polar granule are absent, but a sporocyst residuum, Stieda body, and substiedal body are present. The ellipsoidal oocysts of E. cryptobarretti measure 24 to 35 by 18 to $22 \mu$ (mean 29.8 by $20.6 \mu$ ) with distinct, elongate bulb-shaped sporocysts 13 to 18 by 7 to $11 \mu$ (mean 15.2 by $8.4 \mu$ ). A micropyle, sporocyst residuum, and Stieda body are present, but a polar granule and oocyst residuum are absent. Ellipsoidal oocysts of E. princepsis measure 19 to 24 by 15 to $19 \mu$ (mean 21.5 by $17.3 \mu$ ) with ovoid sporocysts 10 to 14 by 5 to $8 \mu$ (mean 12.3 by $7.3 \mu)$. A micropyle, polar granule, sporocyst residuum, and Stieda body are present, but an oocyst residuum is absent. Ovoid oocysts of E. calentinei measure 26 to 32 by 18 to $23 \mu$ (mean 28.5 by $20.0 \mu$ ) with ovoid sporocysts 10 to 14 by 6 to $9 \mu$ (mean 12.0 by $7.4 \mu$ ). A polar granule is absent, but a micropyle, oocyst and sporocyst residuum, and Stieda body are present. The in vitro excystation of sporozoites of E. cryptobarretti and E. calentinei is described. Sporozoites of E. banffensis and E. princepsis did not excyst after exposure to the excysting fluid for $60 \mathrm{~min}$. Possible reasons for this are discussed.
\end{abstract}

The first report of coccidia of pikas (Ochotona princeps) from North America was by Barrett and Worley (1970) in Montana, but they did not describe oocysts. Recently, Lepp et al. (1972a, b) and Duszynski and Brunson (1972) described oocysts from pikas in Canada and Colorado, respectively.

During July and August 1970, 30 pikas were collected from three mountain sites in two counties in Colorado. The localities of the hosts varied from 11,000 to $13,200 \mathrm{ft}$ above sea level. Intestinal contents from each host were examined for coccidia and four species of Eimeria were observed. One of the Eimeria, E. banffensis, was recently described (Lepp et al., 1972b) and additional data on its structure are presented. The other three Eimeria species are described as new.

\section{MATERIALS AND METHODS}

All techniques involved in collecting and processing fecal material, measuring, studying, and crushing oocysts, and excysting sporozoites were previously reported (Duszynski and Brunson, 1972). Measurements are in microns with the means given in parentheses following the ranges.

Received for publication 13 April 1972.

\section{RESULTS AND DISCUSSION}

Eimeria banffensis Lepp, Todd, and Samuel, 1972 (Figs. 1-3)

\section{Description}

Oocysts subspherical (Fig. 1); oocyst wall of uniform thickness, about 2 , consisting of 2 layers: outer layer green, $>1$, finely pitted (Fig. 2); inner layer yellow, $<1$, smooth (Fig. 2); micropyle, oocyst residuum, and polar granule absent; sporulated oocysts $(n=100,15$ to 35 from each of 4 host specimens) 23 to 34 by 18 to 25 (27.6 by 23.0 ), with shape indices 1.04 to 1.36 (1.20); sporocysts ovoid, 10 to 16 by 7 to 10 ( 12.5 by $8.5)$, with shape indices 1.22 to 1.70 (1.46); Stieda body present with closely apposed substiedal body (Fig. 3); sporocyst residuum granular, in a diffused band between sporozoites (Fig. 3 ); structure of sporozoites in intact sporocysts difficult to distinguish.

Host: Ochotona princeps; Larimer and Clear Creek counties, Colorado.

Location in host: Unknown. Oocysts recovered from contents of small and large intestines.

Prevalence: Present in 7 of 30 pikas examined. These included 5 of 14 hosts collected on Mt. Evans (elev. 12,800 to $13,200 \mathrm{ft}$ ) and 1 of 4 collected on Goliath Peak (elev. 11,600 to 12,000 $\mathrm{ft}$ ), both in Clear Creek County and 1 of 12 collected from Crown Point (elev. 11,000 to 11,500 $\mathrm{ft}$ ) in Larimer County.

Sporulation time: Most oocysts were completely sporulated after $72 \mathrm{hr}$ at $30 \mathrm{C}$. 
Excystation: Sporozoites of this species did not excyst when treated with excysting fluid as described elsewhere (Duszynski and Brunson, 1972; Hammond et al., 1970). The optical density of the sporocyst wall changed when exposed to the excysting solution and the Stieda body and sporocyst contents became indistinct and apparently dissolved. Nothing more happened to most sporocysts observed, even after exposure to the excysting fluid for $60 \mathrm{~min}$. In some sporocysts, however, the granular residua and a homogeneous fluid were forcibly ejected, leaving the sporocysts empty. In these instances, no sporozoites were ever seen, either within or outside the sporocysts.

\section{Remarks}

The time during patency when oocysts are measured may be important in accurately determining their size (Duszynski, 1971). To obtain representative structural dimensions of the four Eimeria spp. observed by us, oocysts from several host specimens were measured for each species on the assumption that oocysts were collected on different days of the patent period.

Eimeria banffensis was described by Lepp et al. (1972b) from O. princeps collected near Banff, Alberta, Canada. The oocysts described by these authors closely resemble those seen by us. According to both descriptions, the oocysts are subspherical, lack a micropyle and an oocyst residuum. Our mean measurements of oocyst length and width were about $2 \mu$ smaller than corresponding parameters reported by Lepp et al. (1972b), but the oocyst shape indices were nearly identical. Only a few discrepancies exist between the two reports. We never observed spherical oocysts. They described a polar granule about $2 \mu$ in diameter, but a similar structure was never seen by us.

This report constitutes a new geographic record for $E$. banffensis and adds photomicrographs (Figs. 1-3) lacking in the original description. We feel it absolutely necessary to support structural descriptions with photographs because line drawings represent interpretational schematization and do not show the variability seen with a microscope.

\section{Eimeria cryptobarretti sp. n.} (Figs. 4-14, 27)

\section{Description}

Oocysts ellipsoid; oocyst wall of uniform thickness, about 2.1, consisting of 2 layers: outer layer brown and rough (Figs. 4, 5), about 1 thick, usually has debris clinging to it; inner layer smooth, about 1; micropyle not apparent in intact oocyst (Fig. 5), but when outer layer of wall is broken (Fig. 6) the smooth inner layer is slightly flattened and thinner at one end giving appearance of a micropyle (Fig. 7); oocyst residuum and polar granule absent; sporulated oocysts $(n=200,21$ to 27 from each of 8 host specimens) 24 to 35 by 18 to 22 ( 29.8 by 20.6 ), with shape indices 1.26 to 1.78 (1.45); sporocysts distinctive in shape (Figs. 8,9 ), 13 to 18 by 7 to 11 ( 15.2 by 8.4 ), with shape indices 1.50 to 2.08 (1.82); Stieda body present (Fig. 8); end of sporocyst opposite Stieda body distinctly pointed (Fig. 9); sporocyst residuum present, usually a compact, spherical mass (Figs. 6, 7), but sometimes as diffuse granules (Fig. 8); sporozoites $(n=10)$ banana-shaped, 2 to 3.5 by 13.5 to 17 ( 2.5 by 15.2 ); each sporozoite with a large posterior refractile globule and another smaller one just anterior to it (Figs. 13, 14).

Host: Ochotona princeps; Larimer and Clear Creek counties, Colorado.

Location in host: Unknown. Oocysts recovered from contents of small and large intestines.

Prevalence: Present in 17 of 30 pikas examined. These included 6 of 14 hosts collected on Mt. Evans, 3 of 4 from Goliath Peak, and 8 of 12 from Crown Point.

Sporulation time: Most oocysts were completely sporulated after $72 \mathrm{hr}$ at $30 \mathrm{C}$.

Excystation: The sporozoites began active movement 1 to $10 \mathrm{~min}$ after the excysting fluid reached the sporocysts. This activity varied in intensity from rapid to slow and was interrupted by moments of complete inactivity. Before sporozoite activity began, the Stieda body disappeared; as the sporozoites began moving, the sporocyst wall became increasingly transparent (Figs. 9-11). Just before excystation, the sporocyst residuum "exploded" in the majority of instances observed; immediately thereafter the sporozoites rapidly left the sporocyst. Whether excystation was triggered by the fragmenting residuum or whether this fragmentation resulted from a rapid change in pressure within the sporocyst is uncertain. After excystation, only the transparent wall of the sporocyst remained (Fig. 12). Total time for complete excystation was 15 to $60 \mathrm{~min}$ after addition of the excysting solution.

\section{Remarks}

The intact oocyst of this species does not resemble any of the oocysts previously described from pikas as tabulated by Lepp et al. (1972a). However, with the rough, outer oocyst wall removed, the oocyst of this species (Fig. 7) closely resembles the oocyst of $E$. barretti as drawn by Lepp et al. (1972a). 


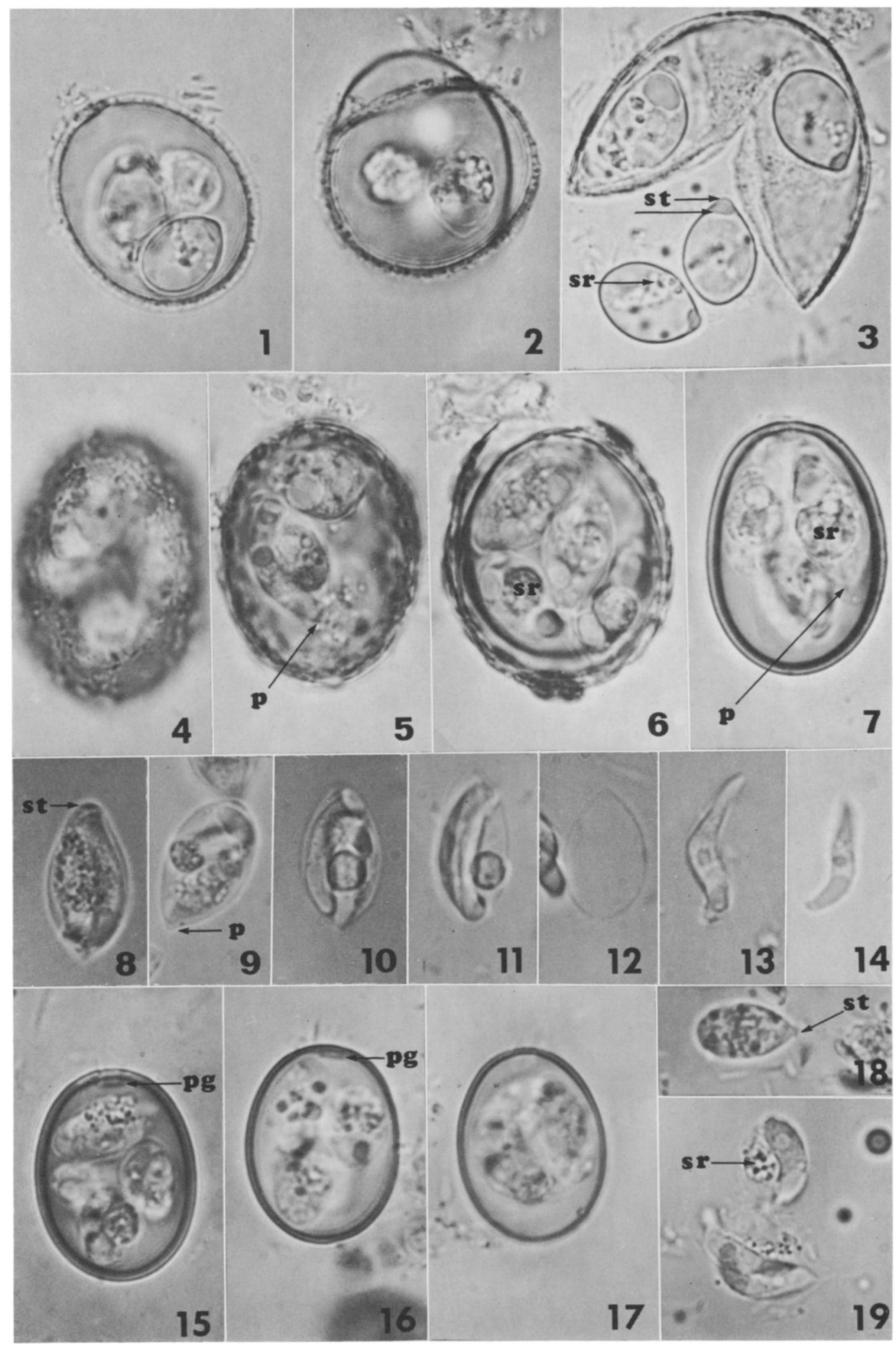




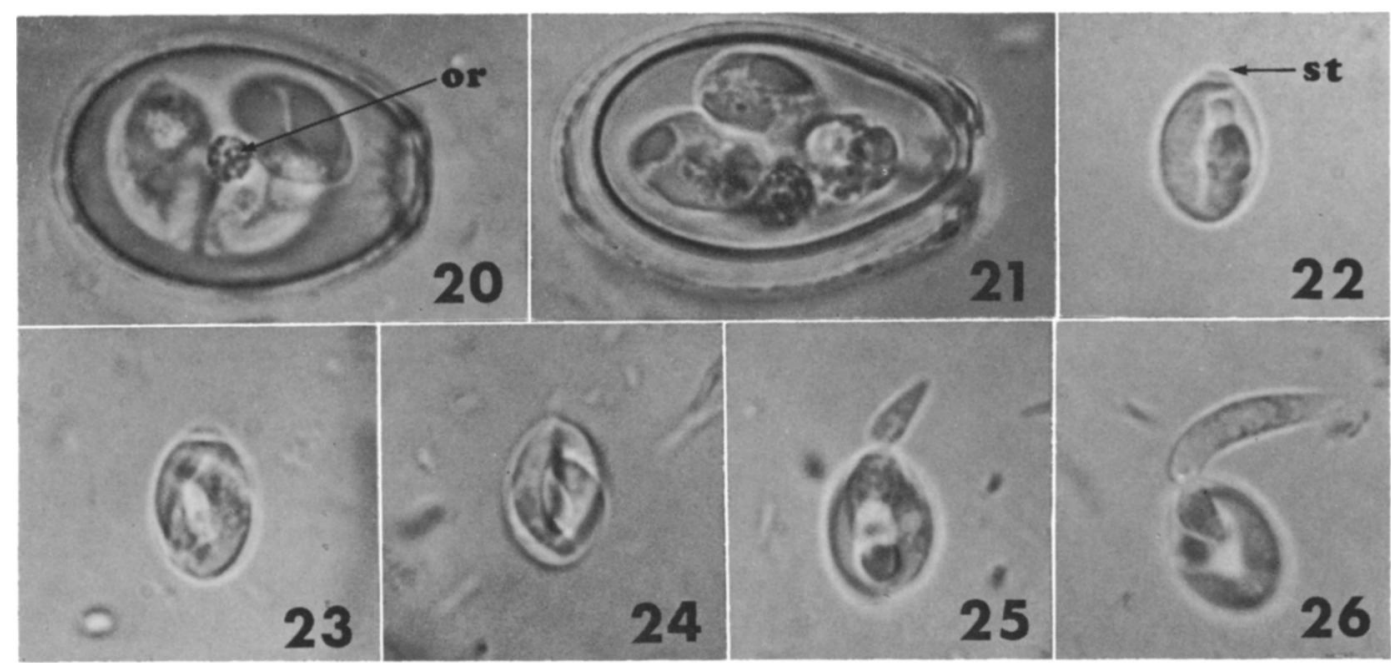

Figures 20-26. Eimeria calentinei. 20. Sporulated oocyst showing micropyle and oocyst residuum. 21. Outer layer of oocyst wall being broken off. 22. Sporocyst before addition of excysting fluid showing Stieda body. 23, 24. Sporocysts after addition of excysting fluid; note disappearance of Stieda body and increasing transparency of sporocyst wall. 25, 26. Sporozoite slowly excysting after repeated reentry into sporocyst.

Fifty sporulated oocysts without their outer layer measured 27 to 33 by 19 to 22 (28.9 by 20.7), with shape indices 1.29 to 1.63 (1.44). These figures are similar to measurements for E. barretti (Lepp et al., 1972a). However, the absence of a polar granule and the unique shape of the sporocysts distinguish sporulated oocysts of E. cryptobarretti in which the outer layer of the oocyst wall is removed from those of $E$. barretti. This outer layer apparently does not contribute much to gross length-width dimensions as 50 intact sporulated oocysts measured 27 to 35 by 19 to $22(30.7$ by 20.7 ), with shape indices 1.33 to 1.68 (1.48).

\section{Eimeria princepsis sp. $\mathrm{n}$.} (Figs. 15-19, 28)

\section{Description}

Oocysts ellipsoid to subspherical (Figs. 15, $16)$; oocyst wall smooth, of uniform thickness, about 1 ; number of wall layers probably 1 as we never could see an inner layer by crushing oocysts or by using friction of the cover slip; micropyle, if present, indistinct; a small, almost square polar granule usually present below area where micropyle may be located, closely apposed to oocyst

Figures 1-26. All figures are photomicrographs of living organisms. $\times 2,000$. Abbreviations: or, oocyst residuum; p, pointed posterior tip of sporocyst; pg, polar granule; sr, sporocyst residuum; st, Stieda body.

Figures 1-3. Eimeria banffensis. 1. Sporulated oocyst in optical cross section. 2. Oocyst with speckled outer layer of oocyst wall partially separated from smooth inner layer. 3. Sporocysts showing Stieda body and substiedal body (arrow).

Figures 4-14. Eimeria cryptobarretti. 4. Sporulated oocyst showing rough outer layer of oocyst wall. 5. Sporulated oocyst in optical cross section; note pointed tip of sporocyst. 6. Outer layer of oocyst wall being broken off. 7. Sporulated oocyst with rough, outer layer of oocyst wall removed showing pointed tip of sporocyst. 8. Sporocyst before addition of excysting fluid showing Stieda body. 9-11. Sporocysts after addition of excysting fluid; note pointed tip of sporocyst (cf. Figs. 5-9), disappearance of Stieda body, and increasing transparency of sporocyst wall. 12. Empty sporocyst immediately after excystation. 13, 14. Sporozoites.

Figures 15-19. Eimeria princepsis. 15, 16. Sporulated oocysts in optical cross section showing location of square polar granule. 17. Unsporulated oocyst without unique polar granule. 18. Intact sporocyst showing Stieda body. 19. Crushed sporocysts showing residua and sporozoites. 

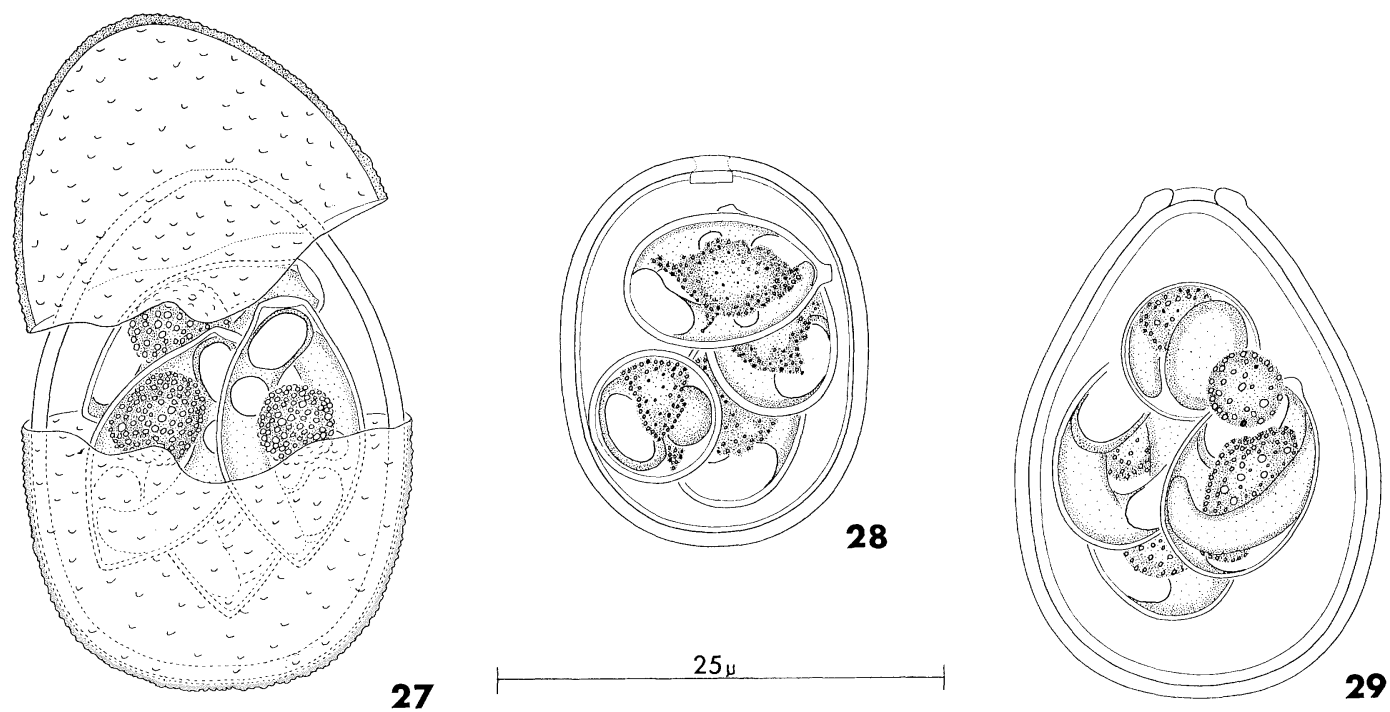

Figures 27-29. Sporulated oocysts. 27. Eimeria cryptobarretti. 28. E. princepsis. 29. E. calentinei.

wall (Figs. 15, 16); this uniquely located polar granule not present in unsporulated oocysts (Fig. 17); oocyst residuum absent; sporulated oocysts ( $n=33,1$ to 20 from each of 5 host specimens ) 19 to 24 by 15 to 19 ( 21.5 by 17.3 ), with shape indices 1.12 to 1.40 (1.25); sporocysts ovoid, 10 to 14 by 5 to 8 ( 12.3 by 7.3 ), with shape indices 1.50 to 2.00 (1.63); Stieda body present as distinct knob at apex of sporocyst (Fig. 18); sporocyst residuum granular, usually scattered throughout sporocyst, but sometimes present as compact spherical mass (Fig. 19); sporozoites arranged side by side tightly within sporocyst; each sporozoite with a posterior refractile globule and probably a second one just anterior to it.

Host: Ochotona princeps; Larimer and Clear Creek counties, Colorado.

Location in host: Unknown. Oocysts recovered from contents of small and large intestines.

Prevalence: Present in 11 of 30 pikas examined. These included 5 of 14 hosts collected on Mt. Evans, 1 of 4 from Goliath Peak, and 5 of 12 from Crown Point.

Sporulation time: Many of the oocysts were sporulated after $72 \mathrm{hr}$ at $30 \mathrm{C}$.

Excystation: Sporozoites of this species did not excyst when the sporocysts were exposed to excysting fluid. No sporozoite movement was seen even after sporocysts were exposed to the excysting solution for $60 \mathrm{~min}$.

\section{Remarks}

Among the oocysts described from pikas, as tabulated by Lepp et al. (1972a), only those of $E$. erschovi and E. daurica somewhat resemble the structure of $E$. princepsis because all three have similar oocyst dimensions.
Eimeria princepsis differs from both in oocyst shape, being narrower than E. erschovi and broader than E. daurica. Eimeria erschovi has a distinct micropyle not seen in E. princepsis and neither E. erschovi nor E. daurica were reported to have a polar granule. The sporocysts of E. erschovi and E. daurica apparently do not possess a characteristic knoblike Stieda body and are 20 to $40 \%$ smaller than the sporocysts of E. princepsis. These structural differences plus geographic isolation and host differences suggest that $E$. princepsis is a distinct form.

\section{Eimeria calentinei sp. $n$.}

(Figs. 20-26, 29)

\section{Description}

Oocysts ovoid, widest in middle and tapering toward micropyle (Figs. 20, 21); wall thickness about 2, composed of 2 layers: yellow, smooth outer layer of irregular thickness, about 1 , thinnest at end opposite micropyle and thickest on sides and around margin of micropyle; inner layer orange, uniform in thickness, about 1 ; distinct micropyle 3 to 7 (4.4) wide; oocyst residuum well defined, spherical, 3 to 6 wide (Fig. 20); polar granule absent; sporulated oocysts $(n=50$, 25 from each of 2 host specimens) 26 to 32 by 18 to 23 ( 28.5 by 20.0 ), with shape indices 1.30 to 1.67 (1.43); sporocysts ovoid (Fig. 22), 10 to 14 by 6 to 9 ( 12.0 by 7.4 ), with shape indices 1.38 to 2.00 (1.63); Stieda body a distinct knob at end of sporocyst (Figs. 22, 23); sporocyst residuum granular, diffuse to spherical; sporozoites 
banana-shaped ( $n=10$ ), 2 by 18 to 21 , with single, large, posterior refractile globule; nucleus located anterior to refractile globule in about center of sporozoite; no noticeable nucleolus; sporozoites folded and tightly packed within sporocyst (Fig. 22).

This species is named for Dr. Robert L. Calentine, Department of Biology, Wisconsin State University, River Falls, for his contributions to parasitology in both teaching and research.

Host: Ochotona princeps; Larimer County, Colorado.

Location in host: Unknown. Oocysts recovered from contents of small and large intestines.

Prevalence: Present in 4 of 30 pikas examined. These included 4 of 12 hosts collected from Crown Point in Larimer County. None of 18 hosts from the 2 collection sites in Clear Creek County were seen to harbor this parasite.

Sporulation time: Most oocysts were completely sporulated after $72 \mathrm{hr}$ at $30 \mathrm{C}$.

Excystation: The sporozoites became active from $30 \mathrm{sec}$ to $12 \mathrm{~min}$ after the excysting solution reached the sporocyst. After 2 min of exposure to the excysting fluid, the Stieda body changed in optical density, quickly became indistinct, and seemed to disappear (cf. Stieda body in Figs. 22-24). At the same time, the sporocyst wall became transparent (Fig. 24). About 2 min after activity started, the sporozoites began to excyst. Excystation occurred less rapidly than in Isospora marquardti (Duszynski and Brunson, 1972) and E. cryptobarretti. Each sporozoite would probe the Stieda body area of the sporocyst, protrude its anterior end through the opening, and then withdraw into the sporocyst. This process was repeated many times; each time the sporozoite would progress farther out of its sporocyst. When only the posterior part of the sporozoite (containing the large refractile globule) remained in the sporocyst (Fig. 26), the sporozoite would gyrate as if attempting to free itself. In only one instance was a sporozoite seen to completely excyst. All other sporozoites remained with the posterior $1 / 4$ of their body inside the sporocyst (Fig. 26), apparently unable to completely excyst.

\section{Remarks}

In comparing the oocysts of pika coccidia which have a micropyle, $E$. calentinei differs from $E$. barretti in oocyst size and shape, in the structure and thickness of the oocyst wall, in lacking a polar granule, and in having an oocyst residuum. It differs from $E$. erschovi in oocyst size and shape, in the structure and thickness of the oocyst wall, and in having larger sporocysts. It differs from E. metelkini in oocyst size and shape, in having a twolayered wall, and in the size and shape of the sporocysts. Finally, it differs from E. ochotona in oocyst size and shape, in having a twolayered wall, and in having considerably larger sporocysts which possess residua.

In the present and in a previous study (Duszynski and Brunson, 1972) we exposed the sporocysts of five species of coccidia from $O$. princeps to a trypsin-sodium taurocholate excysting fluid ( $\mathrm{pH}$ 7.5) and recorded our observations for $60 \mathrm{~min}$. Excystation did not occur in two of the five species. This may be due to any of the following reasons: (a) the sporozoites within the sporocysts observed were dead; (b) a longer exposure time was necessary; (c) the oocysts (merely in transit through the gut) were from a coccidium not normally a parasite of $O$. princeps and that parasite did not respond to the particular excysting solution used by us; and (d) additional or different stimuli were needed to initiate excystation in vitro.

In the case of $E$. banffensis, dead sporozoites seemed responsible for the lack of excystation because sporozoite structure was difficult to distinguish within the sporocysts. Factors (b) and (d) (above) were apparently not responsible since certain structural changes took place in sporocysts exposed to the excysting fluid. Also, it seems likely that $E$. banffensis is a common parasite of $O$. princeps as it was found in $5.9 \%$ of 34 hosts in Canada (Lepp et al., 1972b) and in $23.3 \%$ of 30 hosts from Colorado in this study.

Sporozoites of $E$. princepsis also did not excyst when exposed to the excysting solution used by us. The sporozoites were clearly seen within the sporocyst so it is assumed they were viable. Although this species was not reported by Lepp et al. (1972a, b) in pikas from Canada, it is probably a common parasite in the Colorado pika because it occurred in $36.3 \%$ of the hosts examined in this study. Since no structural changes were seen to occur in the sporocyst after $60 \mathrm{~min}$ exposure to the excysting fluid, perhaps factor (d) was necessary to trigger excystation; however, factor (b) may also be important. Oocysts of different coccidian species are known to excyst at different rates; in certain instances the rate of excystation is directly correlated with the distance which must be traveled in the digestive tract 
to reach the usual site of endogenous development (Hammond, 1971). Thus, E. princepsis may undergo its endogenous cycle in the posterior portions of the gut and therefore need a longer exposure to the stimuli which trigger the excystation process.

\section{LITERATURE CITED}

Barrett, R. E., AND D. E. Worley. 1970. Parasites of the pika (Ochotona princeps) in two counties in South-central Montana, with new host records. Proc. Helm. Soc. Wash. 37: 179-181.

Duszynski, D. W. 1971. Increase in size of Eimeria separata oocysts during patency. J. Parasit. 57: 948-952.

, AND J. T. Brunson. 1972. The structure of the oocyst and the excystation process of
Isospora marquardti sp. $\mathrm{n}$. from the Colorado pika, Ochotona princeps. J. Prot. 19: 257259.

Hammond, D. M. 1971. The development and ecology of coccidia and related intracellular parasites. In A. M. Fallis (ed.), Ecology and Physiology of Parasites. Univ. of Toronto Press, Toronto.

-, J. V. Ernst, and B. Сhobotar. 1970. Composition and function of the substiedal body in the sporocysts of Eimeria utahensis. J. Parasit. 56: 618-619.

Lepp, D. L., K. S. Todd, Jr., and W. M. Samuel. 1972a. Four new species of Eimeria (Protozoa: Eimeriidae) from the pika Ochotona princeps from Alberta and $O$. pallasi from Kazakhstan. J. Prot. 19: 192-195.

- — AND - 1972b. Eimeria banffensis n. sp. (Protozoa: Eimeriidae) from the pika, Ochotona princeps, from Alberta. Tr. Am. Micr. Soc. In press.

ANNOUNCEMENT • . .

\section{Annual Meeting Southeastern Society of Parasitologists}

The Southeastern Society of Parasitologists will have its annual meeting with the Association of Southeastern Biologists at Western Kentucky University, Bowling Green, Kentucky, 12-14 April 1973. Participation and attendance of graduate students and professional parasitologists will be welcomed. For further information, please write to Dr. James S. McDaniel, Program Officer, Department of Biology, East Carolina University, Greenville, North Carolina 27834. 